\title{
A universidade federal do Amapá e a comissão de heteroidentificação: entraves, desafios e possibilidades
}

\author{
The federal university of Amapá and the heteroidentification commission: \\ obstacles, challenges and possibilities
}

Miriam Carvalho da Silva Especialista em Política Educacional Universidade Federal do Amapá - UNIFAP.

Macapá, Amapá - Brasil. almeida.juniog@gmail.com

Elivaldo Serrão Custódio

Doutor em Teologia Universidade Federal do Amapá - UNIFAP.

Macapá, Amapá - Brasil. elivaldo.pa@hotmail.com

\begin{abstract}
Resumo: A presente pesquisa tem por objetivo analisar a constituição do processo de formação da comissão de heteroidentificação na Universidade Federal do Amapá (UNIFAP), assim como o seu credenciamento. Para isso, realizou-se uma pesquisa qualitativa exploratória-reflexiva de cunho bibliográfico e documental. Os resultados apontam que a UNIFAP já regulamentou três comissões e com base nos dados, apenas duas seguem a obrigatoriedade de diversidade de cor e presença de pesquisadores com conhecimentos e capacitações acerca das relações raciais no Amapá, conforme é indicada na Portaria Normativa utilizada pela universidade e apresentada nos editais de ingresso universitário. Os dados apontam ainda uma necessidade de que as comissões sejam compostas por diversidades de cor e gênero, além de pesquisadores e militantes do movimento negro, com vistas às singularidades de cada região do Brasil.
\end{abstract}

Palavras chave: comissão de heteroidentificação; ações afirmativas; UNIFAP; Amapá.

Abstract: This research aims to analyze the constitution of the formation process of the heteroidentification commission at the Federal University of Amapá (UNIFAP), as well as its accreditation. For this, an exploratory-reflective qualitative research of bibliographic and documentary nature was carried out. The results show that UNIFAP has already regulated three commissions and based on the data, only two followed the mandatory color diversity and the presence of researchers with knowledge and training about racial relations in Amapá, as indicated in the Normative Ordinance used by the university and presented in the university admission notices. The data also point to a need for the commissions to be composed of diversities of color and gender, in addition to having researchers and activists from the black movement, in view of the singularities of each region in Brazil.

Key-words: heteroidentification commission; affirmative actions; UNIFAP; Amapá.

Cite como

(ABNT NBR 6023:2018)

SILVA, Miriam Carvalho; CUSTÓDIO, Elivaldo Serrão. A universidade federal do Amapá e a Comissão de heteroidentificação: entraves, desafios e possibilidades. Dialogia, São Paulo, n. 39, p. 1-21, e20426, set./dez. 2021. Disponível em: https://doi.org/10.5585/39.2021.20426.

American Psychological Association (APA)

Silva, M. C., \& Custódio, E. S. (2021, set./dez.) A universidade federal do Amapá e a comissão de heteroidentificação: entraves, desafios e possibilidades. Dialogia, São Paulo, 39, p. 1-21, e20426. https://doi.org/10.5585/39.2021.202426. 
Introdução

As comissões de heteroidentificação são regulamentadas pela Portaria Normativa . $^{\circ}$ 04, de 6 de abril de 2018, e correspondem a mais uma estratégia desenvolvida para auxiliar em concursos públicos a fim de evitar fraudes em vagas reservadas para pretos e pardos nos editais. Dessa forma, esse mecanismo também passou a ser utilizado pelas instituições de ensino superior e institutos federais em diversos estados do país, dado os crescentes casos de fraudes nas universidades, após o Supremo Tribunal Federal (STF) sancionar a Lei n. ${ }^{\circ}$ 12.711, conhecida popularmente como lei de cotas (RIOS, 2018; SILVA, et al., 2020). Ou seja, a comissão é um complemento à autodeclaração, uma vez que dará veracidade à informação fornecida pelo candidato.

Alguns casos de fraudes nas autodeclarações podem refletir o real desconhecimento de parte da população brasileira sobre como se autodeclarar, mas não se pode negar o racismo estrutural por trás da utilização de artifícios para burlar a verificação da informação fornecida pelo candidato, como o uso de maquiagens, perucas e roupas compridas (VAZ, 2018). Além da presença de discursos que alegam favorecimento para a população negra em relação à reserva de vagas em processos seletivos para ingresso universitário, sendo desenvolvidos pensamentos como a sua inconstitucionalidade e que todos deveriam possuir os mesmos benefícios diante de um processo seletivo (BATISTA, 2020; MUNANGA, 2007).

Todavia, tais discursos ignoram todas as vivências experienciadas pelo negro no Brasil, que fora lançado a própria sorte após a abolição da escravatura, sem direitos como o acesso à educação, sendo retirado dos cativeiros e colocado nas periferias das cidades, sempre como alvo de atos genocidas praticados a partir do racismo estrutural que é permeado no país (NASCIMENTO, 1978). Diante disso, as universidades tornaram-se locais destinados e ocupados predominantemente por pessoas brancas, o que dificultou a ascensão do negro por via da educação, apesar das políticas de ações afirmativas.

A considerar este cenário que, ainda, se faz presente, algumas universidades influenciadas pelo movimento negro interno e externo a elas, como a Universidade Estadual do Rio de Janeiro (UERJ) e a Universidade de Brasília (UnB), iniciaram as suas movimentações logo após a conferência de Durban em 2001, mesmo antes da garantia por lei para reserva de vagas destinada à população negra (SITO, 2013). E, no decorrer dos anos, as demais universidades brasileiras passaram a realizar a reserva de vagas, principalmente após a Lei n. ${ }^{\circ}$ 12.711, incluindo a Universidade Federal do Amapá (UNIFAP) a qual passou a reservar vagas 
nos editais de ingresso universitário para pretos e pardos somente por força de lei no ano de 2013.

Desenvolveu-se esta pesquisa a partir da problemática de como vem se constituindo o processo de formação e o credenciamento da comissão de heteroidentificação na UNIFAP. E diante dessas informações, objetivou-se através de uma pesquisa qualitativa exploratóriareflexiva de cunho bibliográfico e documental (GIL, 2008; MELUCCI, 2005), analisar essa constituição do processo de formação, assim como o credenciamento da comissão de heteroidentificação na universidade, a qual é a primeira do estado que implementou uma comissão desta natureza nos processos seletivos para ingresso nos cursos de graduação.

Portanto, diante deste contexto, a pesquisa está dividida em cinco seções. Na primeira seção apresenta-se algumas considerações sobre a política de ações afirmativas de heteroidentificação. Em seguida, discorre-se sobre a implementação da comissão de heteroidentificação no Amapá: o caso da UNIFAP, bem como a capacitação dessa comissão. Posteriormente, traz-se os métodos utilizados pela comissão na UNIFAP. Em seguida apresenta-se os resultados e discussões da pesquisa e por fim, as considerações finais

\section{Política de ações afirmativas}

As políticas de ações afirmativas tratam-se de um conjunto de medidas planejadas pelo Estado e voltadas para grupos discriminados e vitimados através da exclusão social, seja no presente ou no passado, que objetivam a busca pela eliminação de desigualdades e segregações ainda existentes na sociedade. Por meio das ações afirmativas e das políticas que as compõem, há a busca por equidade e reparações históricas, visando a oportunidade e presença diversificada nos mais diversos locais. Tais políticas possuem período de duração definido, portanto, podem deixar de estar em vigência após o período estipulado ou passarem por análise e continuarem em vigor, seja ao nível nacional, local ou institucional (SILVÉRIO, 2007).

Conforme é informado por Munanga (2007), o debate em volta das políticas de ação afirmativa, e, principalmente, de cotas que geram benefícios para alunos negros e pobres no ensino público universitário se dá a partir de um quadro de desigualdades sociais e raciais explícitas e que se acumulam ao longo dos anos, entre brancos e negros.

A luta do movimento negro pela busca de direitos e acesso à educação pública são lutas antigas no Brasil. A busca pela democratização das universidades se fez fortemente presente desde a década de 1980 nos movimentos sociais negros, porém, foi no ano de 2001, durante a III Conferência Mundial contra o Racismo, a Discriminação Racial, a Xenofobia e as Formas 
de Intolerância Correlatas, realizado na cidade de Durban, na África do Sul, que se incentivou a implementação das políticas de ações afirmativas no cenário latino-americano (SILVÉRIO, 2007; SITO, 2013).

$\mathrm{Na}$ Carta de Durban, o Brasil se comprometeu, após reconhecer a existência das diversas formas de violências praticadas contra a população negra brasileira, trabalhar na promulgação de leis e estratégias políticas, econômicas e sociais. Assim sendo, o reconhecimento da participação ativa e atenta para os casos de discriminação racial é crucial para a diminuição de desigualdades existentes no território nacional (BRASIL, 2001).

O plano de ação apresentado em Durban e assinado por diversos países, dentre eles o Brasil, teve impacto direto nos países latino-americanos, os quais se viam como democracias raciais, contudo foram comparados em seus posicionamentos, como semelhantes ao apartheid (SILVÉRIO, 2007; SITO, 2013). Tal impacto ocorreu devido à ideia de que no Brasil, por exemplo, não existia racismo, concepção influenciada principalmente pela obra de Gilberto Freyre. Essa obra coloca o país como uma civilização tropical, que possui características como a mestiçagem e a democracia racial, o que, de certa forma, tendeu a demonstrar que essa mistura de raças possuía vantagem em relação à outras nações (OLIVEN; BELLO, 2017).

Essa ideia utópica de democracia racial, segundo Dantas, Ferreira e Véras (2017), em evento transcrito intitulado Trajetória entre culturas: Kabengele Munanga, um intérprete africano no Brasil - 2016, é discutida pelo próprio Munanga, que considera o racismo no Brasil como um crime perfeito, afinal, como se denuncia um crime que não se tem aquele que o comete? Outro ponto desenvolvido a partir de tal ideia, trata-se da condição de inferioridade do negro não ligada a origem racial, mas ao fato de pertencerem à população mais pobre do país.

Após a conferência de Durban em 2001, uma das primeiras mudanças que ocorreram foi a implementação de ações afirmativas por reservas de vagas na Universidade Estadual do Rio de Janeiro (UERJ), logo em seguida a Universidade de Brasília (UnB) também adotou o sistema de reservas de vagas para jovens negros e destinando 10 vagas por ano para estudantes indígenas (HOFBAUER, 2006; SITO, 2013).

Apesar desse cenário, essas implementações de ações afirmativas não foram fáceis, ocorreram diversos debates, por muitos acreditarem que tais ações são inconstitucionais e que desta forma, o racismo e segregação seriam fortalecidos (MUNANGA, 2007). No entanto, várias leis foram implementadas, como a Lei n. ${ }^{\circ} 10.639$, de 9 de janeiro de 2003, esta que alterou então a Lei n. ${ }^{\circ}$ 9.394, de 20 de dezembro de 1996, a qual estabelece as diretrizes e bases da educação nacional, a qual passou a incluir no currículo oficial da rede de ensino pública e 
privada, a obrigatoriedade do ensino sobre história e cultura afro-brasileira, e que em 2008 foi alterada e a Lei n. ${ }^{\circ} 11.645$, de 10 de março de 2008, passou a incluir também a obrigatoriedade da história e cultura indígena (BRASIL, 2003; 2008).

Com os debates sobre a ideia de inconstitucionalidade sobre a reserva de vagas, o STF em 2012, sancionou a Lei Federal n..$^{\circ}$ 12.711, de 29 de agosto de 2012, popularmente conhecida como lei de cotas, que garante a reserva de 50\% das vagas ofertadas para ingresso em universidades federais e em instituições federais de ensino técnico de nível médio para pessoas autodeclaradas pretas, pardas e indígenas (PPI) e pessoas com deficiência, e a contar de 2013, todas as instituições de educação superior federal passaram a ter quatro anos para implementála (BRASIL, 2012).

Sobre os concursos públicos, foi garantido pela Lei n. ${ }^{\circ}$ 12.990, de 9 de junho de 2014, a reserva de $20 \%$ das vagas para candidatos que se autodeclarem pretos e pardos (BRASIL, 2014). No que tange as ações afirmativas na UNIFAP, foram implementadas por força da Lei n. ${ }^{\circ} 12.711$ de 2012, a abertura de vagas nos editais ocorreu em 2013 (BRASIL, 2012).

No ano 2017, em razão, também, da Portaria Normativa do Ministério da Educação (MEC) n. ${ }^{\circ}$ 18, de 11 de outubro de 2012, sucedeu a aprovação pelo Conselho Universitário (CONSU) via ad referendum da resolução n. ${ }^{\circ}$ 039, de 29 de novembro de 2017, que trata sobre o estabelecimento das ações afirmativas da universidade, a qual necessita ser avaliada a cada quatro anos e pontua-se que já se encontra sem validade, posto que, após a aprovação via ad referendum, não ocorreu a votação para aprovação em plenário em tempo hábil (AMAPÁ, 2017).

Quando se trata sobre ações afirmativas raciais, encontra-se uma grande lacuna nas publicações oficiais de reuniões do CONSU e atraso em aprovações de resoluções, o que demonstra possível racismo institucional, por via da resistência em agilizar os processos e realizar aprovações, o que permiti que a UNIFAP permaneça com os portões fechados para o PPI. De modo a elucidar sobre o que trata o racismo institucional, Almeida (2020) explica que este configura-se a partir da dominação do poder em diversos espaços, e chega a proporcionar parâmetros de discriminação e favorecimento com base na raça do sujeito, até certo ponto proporciona a hegemonia de um grupo racial.

Pontua-se, então, que o movimento da universidade atravessado pelo racismo institucional, perpassa por várias instituições de ensino. Nesse sentido, demonstra possível desatenção para com as políticas de acesso e permanência da população negra nos espaços que promovem ascensão social no território nacional, como as universidades (SILVÉRIO, 2002). 
Tais apontamentos em relação ao CONSU, também, abrem possibilidades para se pensar a respeito do desenvolvimento das atividades da comissão de heteroidentificação da UNIFAP, e, considerar a análise sobre o racismo institucional.

Portanto, com vistas a compreender um pouco mais sobre a comissão de heteroidentificação e sua implementação na UNIFAP, objetiva-se a seguir, apresentar os percursos históricos para a criação do processo de heteroidentificação, assim como a implementação, capacitações e métodos utilizados nos processos seletivos para ingresso universitário na universidade.

\section{Heteroidentificação: algumas considerações}

O processo de heteroidentificação trata-se de um procedimento complementar à autodeclaração de candidatos pretos e pardos em processos seletivos para discentes de universidades e concursos públicos, que conforme Nunes (2018) apresenta, este processo é realizado por uma comissão, a qual verifica a veracidade da informação fornecida pelo candidato à vaga em sua autodeclaração.

As comissões de heteroidentificação são orientadas com base na Portaria Normativa n. ${ }^{\circ}$ 04, de 6 de abril de 2018, do Ministério de Planejamento, Desenvolvimento e Gestão de Pessoas, que regulamenta o procedimento complementar a autodeclaração dos candidatos negros (BRASIL, 2018). Segundo Rios (2018) e Vaz (2018), tais comissões devem ser compostas por diversidade de gênero e cor, naturalidade (pertencente ao local onde se realizará a heteroidentificação) e integrantes ativos de movimentos sociais. Tais necessidades na composição se dão devido ao racismo estrutural existente no Brasil e a variedade do que é entendido social e subjetivamente como ser negro em cada região do país.

Torna-se importante sinalizar que a Portaria Normativa n. ${ }^{\circ}$ 04/2018 passou a ser utilizada pelas universidades como um instrumento complementar, devido aos inúmeros casos de fraudes raciais nos processos seletivos para ingresso universitário. Todavia, a portaria foi criada com a finalidade destinada para concursos públicos federais no que tange a cargos da administração federal direta, fundacional e autárquica.

Considerando que após a aprovação das Leis n. ${ }^{\circ}$ 12.711/2012, "lei de cotas" e n. ${ }^{\circ}$ 12.990/2014, que corresponde ao ingresso no serviço público, começaram a ocorrer fraudes nos processos seletivos para ingresso universitário e em concursos públicos. Segundo Vaz (2018), alguns dos candidatos que fraudam os processos utilizam maquiagem, perucas, barbas e roupas 
compridas, deixando apenas o rosto descoberto, artifícios que auxiliam em fraudes e que a comissão necessita dar atenção.

Essa fraude cometida nos processos de verificação da veracidade da autodeclaração é considerada crime, pois como apresenta Silva et al. (2020), no texto da Lei n. ${ }^{\circ} 12.990 / 2014$, é previsto punição ao candidato, caso sua declaração for considerada falsa, dando assim, maior apoio jurídico para a formação das comissões de heteroidentificação, e, consequentemente, sua implantação.

Compreende-se, também, que a heteroidentificação compõe as políticas de ações afirmativas e neste processo é possível encontrar duas linhas de pensamentos nos debates sobre o seu uso e aplicação. A primeira linha argumenta que a heteroidentificação proporciona maior objetividade em relação à classificação racial e melhor efetividade nas políticas públicas que são destinadas para as minorias raciais. Essa linha considera uma melhor alocação de tais benefícios. A segunda linha alerta para o perigo do reforçamento de estereótipos estigmatizados de algumas categorias raciais. Cria-se a necessidade de enquadrar os indivíduos analisados em padrões estabelecidos por terceiros, além de abrir espaço para ser interpretada como uma imposição de identidades raciais (RIOS, 2018).

Porém, o que prevalece em meio a esta discussão e necessita ser lembrando, é o fato da heteroidentificação não ser o único método que é utilizado, ou seja, a heteroidentificação não anula a autodeclaração, é, portanto, um complemento, busca a diminuição ou aniquilação de fraudes entre candidatos para ingresso universitário.

A partir do exposto, pontua-se, ainda, que deve ser considerada a raça social do candidato à vaga e não somente como o sujeito se autodeclara. Assim, as comissões recorrem à análise fenotípica do candidato, que não considera se ele possui parentes negros, porque o preterimento a qual vivencia não se dá por ele possuir pais ou avós negros, mas por sua raça social, isto é, como é lido racialmente no seu dia a dia. Todas essas questões evidenciam que o racismo ao qual vivencia diariamente e que lhe retira oportunidades, se dá pela cor de sua pele, seus traços faciais e seu cabelo (FONTOURA, 2018; NUNES, 2018; VAZ, 2018).

Observa-se, então, que algumas universidades brasileiras já estão com as comissões de heteroidentificação devidamente implementadas e em ação, como o caso da Universidade Federal de Ouro Preto (UFOP), que segundo Camilloto e Oliveira (2020), após o recebimento de inúmeras denúncias de fraudes no que diz respeito a autodeclaração dos candidatos, as quais foram apresentadas pelo movimento negro, decidiu em 2017 adotar o procedimento, mesmo antes da existência de qualquer regulamentação interna e externa que fornecesse maior respaldo 
para essa verificação. Nota-se que essa é apenas uma das dificuldades encontradas, todavia não impossibilitou o andamento das atividades.

Outro exemplo trata-se da Universidade Federal do Rio Grande do Sul (UFRGS) que em 2007, em decorrência da demanda do movimento social negro, instituiu o Programa de Ações Afirmativas na Universidade, que ocorreu antes da Lei n. ${ }^{\circ}$ 12.711/2012. Após o aprimoramento do conhecimento de tal política, os movimentos negros internos e externos à UFRGS, também começaram a cobrar posicionamentos da instituição diante das denúncias de fraudes referentes ao acesso de vagas reservadas para candidatos autodeclarados negros (BATISTA; FIGUEIREDO, 2020).

Já a Universidade Federal do Pará (UFPA) até o último processo seletivo para graduação, fazia uso somente da autodeclaração dos candidatos, mas em concordância com o que fora informado em seu site oficial. No primeiro processo seletivo de 2021 a comissão de heteroidentificação implementada na universidade iria analisar a autodeclaração dos candidatos negros (PARÁ, 2021).

Logo, é possível compreender, a partir do que foi exposto até o momento, que as comissões de heteroidentificação são mecanismos desenvolvidos para a garantia de direitos de uma população esquecida e marginalizada, principalmente no que corresponde ao acesso à educação superior nas universidades públicas brasileiras, dentre elas, a UNIFAP, que passou a realizar o processo de heteroidentificação baseada em análise fenotípica no ano de 2020 com candidatos para vagas como discentes em cursos de graduação, temática essa que será desenvolvida a seguir.

\section{Implementação da comissão de heteroidentificação no Amapá: o caso da UNIFAP}

Como citado, ao apresentar informações sobre as ações afirmativas no Brasil, referentes a promulgação da Lei n. ${ }^{\circ} 12.711 / 2012$, os debates dentro e fora das universidades, sobre as vagas serem ocupadas por quem pertencem por direito, foram crescentes e naquele momento, garantidas por lei, sendo tais vagas consideradas constitucionais. Após esse período inicial, foram desenvolvidas formas de verificação das candidaturas dos cotistas nas universidades públicas.

Conforme é apresentado por Silva et al. (2020), as comissões de heteroidentificação não são estratégias novas nas universidades brasileiras, existem desde os anos 2000, quando os primeiros sistemas de ação afirmativa foram implementados de maneira individual em cada 
universidade, mas não possuíam amparo legal que as regulamentassem fora da autonomia da universidade.

Sobre isso, com base na Portaria Normativa n. ${ }^{\circ}$ 04/2018 do Ministério de Planejamento, Desenvolvimento e Gestão de Pessoas, citada anteriormente, a UNIFAP, passou a implementar desde 2019, o processo de heteroidentificação nos editais de processos seletivos para ingresso universitário, entretanto a Universidade não publicou nenhuma resolução ou portaria sobre tal processo implementado no ano citado. É pertinente destacar que a UNIFAP iniciou as suas atividades em 1970 como Núcleo Avançado de Ensino (NEM), ainda, vinculada a UFPA. Nesse ano, implantou assim, o ensino superior no estado do Amapá, e, ofertou cerca de 500 vagas voltadas para o campo do magistério e somente em 1990 com o Decreto n 98.977 , de 2 de março de 1990 foi oficializada a criação da universidade, tornando-se então, uma instituição mantida pela União.

Apesar das informações pontuadas sobre o processo de heteroidentificação na UNIFAP serem até então escassas, no site oficial da universidade é informado que existe uma comissão de heteroidentificação, a qual é responsável pela verificação das informações fornecidas pelos candidatos nos processos seletivos para ingresso universitário (AMAPÁ, 2020d). Foram, portanto, acessadas informações documentais que apresentam o período em que três comissões citadas em portarias foram instituídas. No entanto, para se compreender detalhadamente os pontos que serão apresentados, faz-se necessário, primeiramente, entender o que é solicitado na Portaria n. ${ }^{\circ}$ 04/2018 a qual regulamenta a comissão de heteroidentificação. É colocado que:

\begin{abstract}
Art. $6^{\circ}$ O procedimento de heteroidentificação será realizado por comissão especificamente para este fim. $\S 10^{\circ}$ A comissão de heteroidentificação será constituída por cidadãos: I - de reputação ilibada; II - residentes no Brasil; III - que tenham participado de oficina sobre a temática da promoção da igualdade racial e do enfrentamento ao racismo com base em conteúdo disponibilizado pelo órgão responsável pela promoção da igualdade étnica previsto no $§ 1^{\circ}$ do art. 49 da Lei n. ${ }^{\circ}$ 12.288, de 20 de julho de 2010; e IV-preferencialmente experientes na temática da promoção da igualdade racial e do enfrentamento ao racismo (BRASIL, 2018, p. 2).
\end{abstract}

Conforme é exposto na portaria, é de grande importância que os componentes da comissão estejam capacitados para exercer tal atividade e, sobre isso, Tavares Jr. (2018) apresenta que essa capacitação não deve se dar somente em torno do desenvolvimento da heteroidentificação, ou seja, do ato de avaliação e verificação, mas que deve englobar também uma capacitação que envolva a compreensão da sociedade brasileira e local. Dessa forma, será possível realizar uma leitura das classificações de raça, da sociedade e dos impactos do racismo 
estrutural e institucional. Nesse sentido, é importante, também, que a comissão seja composta por pessoas que já possuam experiência com a temática de promoção da igualdade racial.

Diante disso, no segundo semestre de 2020 foi instituída uma comissão de heteroidentificação e matrícula, composta por cinco membros, através da Portaria n. ${ }^{\circ}$ 0934/2020, para análise da matrícula de alunos cotistas do SISU 2020, 2. a edição (AMAPÁ, 2020). Entretanto, ao verificar a respeito do cumprimento de diversidade de cor e gênero, assim como integrantes pesquisadores e participantes de movimentos sociais, neste caso, principalmente do movimento negro, foi realizada, através da Plataforma Lattes uma busca curricular dos membros da comissão, sendo constatado que dos 4 (quatro) integrantes que tiveram seus currículos lattes encontrados, foi cumprido apenas a diversidade de gênero.

Para a análise de recursos foi instituída, através da Portaria n. ${ }^{\circ}$ 0018/2020 homologada em 2021, uma comissão composta por 5 (cinco) membros e sendo realizada a busca curricular para verificar o cumprimento de diversidade de cor e gênero, assim como integrantes do movimento negro e pesquisadores de temáticas raciais, foi encontrado apenas 1 (um) currículo que apresentasse todas as informações citadas e sobre os demais membros não foram encontradas informações que viessem a corroborar com a pesquisa, o que se considerou que alguns não estavam disponíveis ou não apresentavam dados completos (AMAPÁ, 2021a).

Seguindo nas apresentações das comissões que foram instituídas na universidade, está em vigor através da Portaria n. ${ }^{\circ}$ 0021/2021, a qual versa:

\footnotetext{
Art. 1. ${ }^{\circ}$ - Instituir a Comissão de Heteroidentificação, a qual competirá atuar nas análises dos candidatos cotistas no decorrer do Processo de Seleção para ingresso nos cursos de graduação da UNIFAP (PS 2020), sendo presidida pelo primeiro membro, conforme relação abaixo (BRASIL, 2021b, p. 1).
}

A comissão é composta por servidores da universidade, somando o quantitativo de cinco membros, sendo três destes membros integrantes do Núcleo de Estudos Afro-brasileiros (NEAB/UNIFAP), o que contribui fortemente para as ações e procedimentos. Considera-se, então, a importância da diversidade de gênero e cor, assim como militantes e pesquisadores sobre ações afirmativas, promoção de igualdade racial e relações raciais.

$\mathrm{Na}$ observação os apontamentos apresentados, percebe-se que a primeira comissão instituída pela Portaria n. ${ }^{\circ}$ 0934/2020, conforme os achados e análises, não atendeu ao que é solicitado na Portaria Normativa n. ${ }^{\circ}$ 04/2018, bem como não apresentou ou explicou em seu 
texto qualquer especificidade necessária para a sua realização sem seguir ao que é pedido na portaria de 2018.

\section{Capacitação da comissão de heteroidentificação na UNIFAP}

Anterior a implementação da comissão de heteroidentificação, conforme é disponibilizado no site oficial da universidade, foi realizada uma capacitação em 2019, intitulada $O$ racismo e as ações afirmativas: a heteroidentificação nos concursos públicos, com servidores da UNIFAP, efetivada por uma representante do Ministério da Cidadania (AMAPÁ, 2019). Esse curso visava capacitar os servidores para que, por meio das suas atuações, viessem garantir que o beneficiário de cotas raciais, seja realmente negro.

Em um evento realizado online e disponibilizado na plataforma YouTube no canal do NEAB-UNIFAP, intitulado como Gira de saberes: heteroidentificação e cotas raciais, Cleidiane Nascimento, como representante da reitoria e atual representante de pessoal da UNIFAP, informou que o processo de heteroidentificação até aquele momento, já havia ocorrido em dois processos seletivos para discentes (NEAB-UNIFAP, 2020).

No entanto, realizar uma capacitação sobre heteroidentificação e convidar uma pessoa que desconhece a realidade e a disparidade do estado em relação a outros estados e a população negra, abre espaço para questionamentos e influências sobre a realização com excelência da heteroidentificação, a considerar o que é tido como negro nas variadas regiões do país.

\section{Métodos utilizados pela comissão de heteroidentificação na UNIFAP}

Com a Portaria Normativa n. $^{\circ}$ 04/2018 que regulamenta as comissões de heteroidentificação, é apresentado na seção II, art. $8 .^{\circ}$ e $9 .^{\circ}$, que correspondem aos procedimentos que devem ser adotados, como ocorrerá o procedimento de heteroidentificação e essa informação deverá constar no edital de abertura para vagas. Além disso, é informado que a comissão deverá utilizar exclusivamente o critério fenotípico, assim como não poderá ser aceito qualquer documentação ou registro pretérito que sejam referentes a confirmação em procedimentos anteriores (BRASIL, 2018).

Na Portaria n. ${ }^{\circ}$ 0021/2021 que institui a comissão em vigor na UNIFAP, não é sinalizado como se dará o procedimento de heteroidentificação, somente apresenta que a comissão irá atuar nas análises dos candidatos cotistas para cursos de graduação no decorrer do processo seletivo (AMAPÁ, 2021b). 
Em janeiro de 2020, deu-se início ao surgimento do procedimento de heteroidentificação nos editais de processo seletivo para cursos de graduação da UNIFAP, no entanto, não foi comunicado ao candidato como se daria tal procedimento ou em que momento ocorreria. Com o objetivo de explicar e explicitar o que foi pontuado no edital n. ${ }^{\circ}$ 005/2020 DERCA/UNIFAP e 006/2020 - DERCA/UNIFAP, ambos de convocação para matrícula, os quais foram os primeiros editais de processo seletivo para a graduação da universidade com esse critério, foi apresentado que em consonância com a comissão de heteroidentificação e em obediência à Portaria Normativa n. ${ }^{\circ}$ 04/2018, a universidade exerceria procedimentos que são amparados pela normativa citada, sem maiores detalhes apresentados ao candidato (AMAPÁ, 2020a; 2020b).

Somente no Edital n. ${ }^{\circ}$ 026/2020 - DERCA/UNIFAP, edital de convocação para matrículas, acrescentou-se que, devido à pandemia de Covid-19 e a suspensão das atividades presenciais, seria obrigatória a presença do aluno matriculado na modalidade cotista, quando retornar das atividades presenciais, o que visará a garantia e finalização de sua matrícula, respaldo garantido na Portaria Normativa n. ${ }^{\circ}$ 04/2018 (AMAPÁ, 2020c).

No site oficial da universidade, encontra-se a informação de que a comissão deverá avaliar as informações e documentos apresentados pelo candidato, assim como a realização de uma entrevista com filmagem e captação de áudio, somente depois ocorrerá a decisão como deferido ou indeferido a condição de cotista (AMAPÁ, 2020d). Não é informado qualquer outro método para o procedimento que seja utilizado, como a telepresencial, a partir do uso de recursos tecnológicos de comunicação, liberada pela normativa n. ${ }^{\circ}$ 04/2018, a qual é citada como reguladora do procedimento para os editais citados acima.

Art. $8^{\circ} \S 1 .^{\circ} \mathrm{O}$ edital definirá se o procedimento de heteroidentificação será promovido sob forma presencial ou excepcionalmente e por decisão motivada, telepresencial, mediante utilização de recursos de tecnologia de comunicação (BRASIL, 2018, p. 3).

Destarte, mesmo garantida punição a quem prestar falsa informação nos processos seletivos anteriormente citados, abrem-se possibilidades para que as vagas sejam ocupadas por quem não corresponde à descrição, ou seja, uma pessoa não negra pode vir a ocupar uma vaga destinada a candidatos negros, dado o tempo para tal verificação, como no caso da espera para realização presencial, devido à pandemia de Covid-19. 


\section{Resultados e discussões da pesquisa}

Os estudos sobre as comissões de heteroidentificação racial estão cada vez mais frequentes, devido à implantação nas universidades de forma oficial desde 2018, com a Portaria Normativa n. ${ }^{\circ}$ 04, de 6 de abril de 2018, o que contribui ainda mais para a política de ações afirmativas e para a diminuição de fraudes em processos seletivos, por meio de avaliação fenotípica dos candidatos, a veracidade é verificada pela autodeclaração nos formulários de inscrição, como visto no decorrer da pesquisa. Portanto, as comissões de heteroidentificação devem ter por objetivo serem mais uma forma de garantir o direito de acesso à educação superior da população negra brasileira.

No entanto, apesar de ser uma temática que está sendo trazida para os debates em círculos sociais, nota-se ainda desconhecimento de instituições e parte da sociedade sobre a existência da Portaria n. ${ }^{\circ}$ 04/2018, e da importância das comissões de heteroidentificação em vários âmbitos, principalmente educacionais, a exemplo disso, tem-se o próprio objeto de estudo com recorte para o estado do Amapá. No Amapá, além da UNIFAP, também há a Universidade Estadual do Amapá (UEAP), esta última aplica a lei de cotas nos processos seletivos, mas não possui, até o momento, nenhuma comissão de heteroidentificação.

Isso demonstra e reforça a necessidade de produzir sobre as ações afirmativas, principalmente sobre o Amapá, bem como, ratifica a importância desta pesquisa, sendo uma temática nova e que muito deverá contribuir para os conhecimentos das universidades e da população amapaense quanto à atuação, público de direito e formas de atuação.

Com base nos objetivos da pesquisa, tornou-se possível analisar algumas questões sobre a implantação da comissão no Amapá, com foco especial para a UNIFAP e situações que ainda precisam ser debatidas, como o conhecimento da própria raça no ato de autodeclaração. Segundo Nunes (2018), é possível perceber desconhecimento da população brasileira sobre como se autodeclarar, tendo em vista, o discurso de branqueamento ainda existente no Brasil e o mito da democracia racial.

Portanto, antes de ser desenvolvido sobre a implantação da comissão de heteroidentificação no Amapá, faz-se necessário apontar os achados e análises realizadas sobre conceitos já estabelecidos na sociedade, como raça, identidade racial e racismo, pois se compreende que tais pontos podem vir a implicar diretamente na formação social, cultural e subjetiva do candidato em processos seletivos para ingresso universitário. Possivelmente, o conhecimento dos meandros influenciaria as pessoas que compõem as comissões de 
heteroidentificação racial, tendo em vista, por exemplo, ideias como o pacto narcísico da branquidade trabalhado por Bento (2002) na perspectiva do racismo institucional. Abre-se, então, espaço para ser analisado o racismo estrutural, racismo institucional e as possíveis dificuldades para as ações da comissão.

Dessa maneira, é necessário compreender, antes de tudo, o conceito de raça atrelado a temática da pesquisa. Em apanhado histórico sobre o surgimento deste conceito, Almeida (2020) explica que a raça está ligada à classificações, que primeiro foram dadas para plantas e animais, e mais tarde, por volta do século XVI, passaram a ser dadas aos seres humanos e isso aconteceu em decorrência de conflitos e busca por poder na sociedade.

Partindo dessa perspectiva, torna-se possível compreender a ideia de raça social, a forma como o sujeito é lido e classificado conforme os seus traços e cor da pele, conceito este muito utilizado nas ações afirmativas, pois possui um resultante histórico, cultural e social (RIOS, 2018). Assim sendo, na leitura de raça social, o que vem a ser considerado é a identidade racial e social da pessoa, ou seja, as características fenotípicas e não questões genéticas, como ter avós negros ou ser fruto de relacionamento inter-racial.

Como explicitado no decorrer da pesquisa, o Brasil é marcado por diversos episódios racistas no seu desenvolvimento e que possuem efeitos na população brasileira até a atualidade, Almeida (2020) classifica tal informação como racismo estrutural, pois está presente em todos os âmbitos da sociedade, foi introjetado nas instituições e nos grupos sociais, surgido, por exemplo, nos índices de violência policial contra a população negra e na dificuldade de acesso e permanência na educação, sendo refletido nas divisões de classe, gênero e raça.

Ao analisar estes apontamentos e as informações coletadas referentes as ações afirmativas e sobre a implementação da comissão na UNIFAP, além da dificuldade para encontrar e acessar materiais oficiais da instituição, tornou-se possível pensar a possibilidade de racismo institucional por via da desatenção em relação à aprovação da Resolução n. ${ }^{\circ}$ 039, de 29 de novembro de 2017, esta que é referente a política de ações afirmativas da universidade e a sua renovação que deveria ter ocorrido em 2020. Da mesma maneira que não ocorreram as publicações de portarias em 2019 ou em 2020 no primeiro semestre, referentes a implantação da comissão de heteroidentificação no site oficial da universidade ou repasse de materiais para os profissionais que passaram pela capacitação realizada pelo Ministério da Cidadania do Governo Federal.

Para compreender melhor essa análise, faz-se uso do que é apresentado por Almeida (2020) ao falar sobre racismo institucional que, conforme o autor, este tipo de racismo se dá 
através do estabelecimento de medidas que possuem a raça como critério para manter a hegemonia de determinado grupo no poder. E ao falar de poder, o autor considera todos os tipos de instituições, inclusive as reitorias de universidades e seus departamentos, uma vez que o racismo é a dominação de vários segmentos, como a educação, padrões estéticos e práticas de poder que dificultam de maneira direta ou indireta a ascensão de negros, no caso aqui, por meio da educação.

A não aprovação e desatenção com as políticas de ações afirmativas da universidade que garantem o acesso e permanência dos alunos negros, só reforça a ideia de imposições de barreiras à comunidade negra para o acesso à educação superior (NOGUEIRA; LIMA, 2019). O acesso à educação é garantido por lei e o seu não cumprimento reflete diretamente na tomada de decisões no combate à discriminação racial e promoção de educação e formação antirracista.

Os pontos apresentados até o momento muito se assemelham a política de branqueamento já praticada no país, onde os direitos da população negra foram retirados, buscou-se a eliminação dessa população e neste caso, é possível que a desatenção com a política de ação afirmativa da universidade, não publicação de portaria entre 2019 e o primeiro semestre de 2020; repasse de materiais de estudo para a comissão de heteroidentificação e dentre outros pontos, seja uma forma de permanecer com os portões fechados para negros na universidade.

Os posicionamentos racistas encontrados na universidade durante a pesquisa não se limitam a dificuldade em acessar materiais que deveriam estar publicados de maneira oficial no site da UNIFAP, na página do CONSU em suas pautas, atas e resoluções, mas trata-se, também, das dificuldades impostas para ter acesso às documentações que enfatizam sobre as comissões de heteroidentificação, suas ações, formações e outras informações que são solicitadas na Portaria n..$^{\circ}$ 04/2018, a qual normatiza o procedimento. Informações estas solicitadas via ofício com entrega presencial, sendo protocolado no DERCA e enviado para o e-mail da PROGRAD, por ausência de profissionais na universidade que pudessem protocolar a solicitação naquele período, mas que não tiveram retorno algum.

Tais posicionamentos vão contra o que é imposto no Estatuto de Igualdade Racial, Lei n. ${ }^{\circ}$ 12.288/2010, que tem como objetivo a garantia “à população negra a efetivação da igualdade de oportunidades, a defesa dos direitos étnicos individuais, coletivos e difusos e o combate à discriminação e às demais formas de intolerância étnica" (BRASIL, 2010, p. 1).

A UNIFAP possui, conforme apresentado em seu site oficial, 29 cursos de graduação, dentre eles os cursos de medicina, direito e as engenharias civil e elétrica, que segundo Santos (2017), são cursos culturalmente elitizados e com baixa presença de negros desde os seus 
surgimentos nas universidades públicas e privadas no Brasil, e, que, ainda, continuam no mesmo movimento até os últimos anos.

A respeito da presença negra no Amapá, segundo o IBGE (2012) em seu último censo realizado em 2010, a porcentagem de pessoas que se autodeclararam como pretas foi de $8,7 \%$ e $65,2 \%$ autodeclarada como parda. Essa alta porcentagem de pardos no estado possibilita engendrar indagações a respeito dos atravessamentos sociais, culturais e psicológicos que perpassam pela população amapaense na autodeclaração, vindo a ser uma possibilidade para outras pesquisas.

O desconhecimento sobre as classificações do IBGE também pode interferir diretamente no preenchimento de formulários de candidatura a vagas em processos seletivos para graduação na UNIFAP, principalmente para a utilização de políticas de ações afirmativas, como as cotas raciais. Para isso, pontua-se que no IBGE, a classificação de cor referente a pardo e preto necessita ser compreendida como pertencentes a raça negra e que sim, o pardo em sua maioria das vezes pode ser lido socialmente como negro. Todavia, é importante considerar a disparidade da compreensão sobre como essas pessoas são lidas racialmente nas mais variadas regiões do país.

Com base nessa ideia, questionou-se a princípio, qual o andamento da implantação da comissão de heteroidentificação na UNIFAP, com o intuito de analisar como está se constituindo o processo de formação e credenciamento da comissão de heteroidentificação na UNIFAP, pensando a partir de produções científicas e principalmente por via de documentos oficiais - portarias, resoluções e editais - da universidade.

A princípio, em 2019, ocorreu uma capacitação para os servidores da universidade com uma pessoa de fora do estado, este fato abre a possibilidade para se pensar como se deu a compreensão da população negra amapaense, tendo em vista os variados entendimentos sobre ser negro no país em decorrência, por exemplo, do mito da democracia racial e as ideias negativas desenvolvidas sobre a população negra, o que gera no sujeito, a busca pela fuga do significante negro, na busca pelo branqueamento através de outras palavras (SANTOS, 1998).

Tendo como base os documentos selecionados e citados no decorrer da pesquisa, notase que a comissão selecionada para agir no processo seletivo dos editais n. ${ }^{0}$ 005/2020 DERCA/UNIFAP e n. ${ }^{\circ}$ 006/2020 DERCA/UNIFAP atuou conforme as exigências da Portaria Normativa n. ${ }^{\circ}$ 04/2018, foi apresentado no item 5 (cinco) em ambos os editais de convocação para matrícula, em obediência ao que é solicitado na portaria citada. Porém, não encontraram 
as portarias da instituição que regulamentassem a sua implementação no período de divulgação do edital, mesmo que anterior ou publicada no primeiro semestre de 2020.

Como apresentado no decorrer do texto, três comissões foram instituídas na UNIFAP, contudo apenas duas se adequaram ao que é solicitado na Portaria Normativa n. ${ }^{\circ}$ 04/2018 a respeito de diversidade de cor e gênero, não foi apresentado na Portaria n..$^{\circ}$ 0934/2020 o motivo da ausência de integrantes do NEAB/UNIFAP ou demais pesquisadores e integrantes de movimentos sociais, como o movimento negro amapaense.

Atualmente, a comissão de heteroidentificação que está em vigor, como consta na Portaria n. ${ }^{\circ}$ 0021/2021 da universidade, é composta por pesquisadores e integrantes do movimento negro local, sendo também, três membros pertencentes ao NEAB/UNIFAP, o que possibilita um novo cenário para a realização das atividades que ficam a cargo da comissão (AMAPÁ, 2021b). Apesar de compreendermos que a entrada de integrantes possui grande significado para o movimento negro dentro e fora da universidade, ainda é possível visualizar um longo caminho na luta antirracista dentro da UNIFAP, quando pensamos o ingresso e permanência de negros.

No entanto, no que se observa no andamento de outras universidades com a implantação das comissões e a busca por estratégias, em sua maioria, por via do movimento negro composto por docentes, discentes e demais profissionais e da militância externa a universidade, pode ser percebido que, através de capacitações e estabelecimento concreto com o NEAB/UNIFAP, com acadêmicos integrantes do movimento negro amapaense, pesquisadores e membros da comunidade, seguindo o que a Portaria Normativa n. ${ }^{\circ}$ 04/2018 estabelece e possíveis especificidades que passem a ser adotadas na UNIFAP, as comissões terão muito a contribuir no que corresponde às vagas serem ocupadas por quem as tem por direito e também na verificação de possíveis fraudes que possam ter ocorrido em outros processos seletivos de ingresso universitário realizados na universidade.

Desta maneira, compreende-se que a primeira comissão de heteroidentificação instituída pela Portaria n. ${ }^{\circ}$ 0934/2020 que de acordo com os achados, não possuía registro de membros negros, pode ter enfrentado dificuldades para a sua realização, devido a um possível não letramento racial e ausências de capacitações que detalhassem algumas especificidades, como a questão do pardo e todas as discussões que o circundam. Ressalta-se, então, a necessidade frequente de capacitações e estudos sobre políticas de ações afirmativas e relações raciais para a comissão de heteroidentificação, para outros servidores da universidade e a comunidade em geral. Promover, desta maneira, reflexões e conhecimentos a respeito dos direitos da população 
negra amapaense e possíveis mudanças de posturas e posicionamentos, a considerar o racismo institucional na UNIFAP.

\section{Considerações finais}

Para finalizar os argumentos e análises apresentados no decorrer desta pesquisa, é possível realizar o retorno ao questionamento que provocou movimentações para compreender, a partir de documentos oficiais da universidade, como o processo de formação e credenciamento da comissão de heteroidentificação na UNIFAP está se constituindo referente a atuação em processos seletivos de ingresso universitário.

No estudo foram apontadas algumas implicações sociais ligadas ao racismo e o desconhecimento por parte do candidato sobre cor e raça ao realizar a autodeclaração como preto ou pardo, a fim de utilizar a política de cotas raciais. Atrelou-se, também, a estas análises os casos de fraudes nos processos seletivos universitários e os artifícios (perucas, maquiagens, roupas compridas) utilizados por alguns candidatos. Estes são pontos que reforçam a necessidade da presença de comissões de heteroidentificação nas universidades, como já se faz na UNIFAP.

Percebeu-se em meio a todos os apontamentos, achados e análises, a necessidade, conforme apresentado na pesquisa, que as comissões sejam compostas por diversidades de cor e gênero, além de possuir pesquisadores e militantes do movimento negro, tendo em vista as singularidades de cada região no Brasil. Portanto, conclui-se que, apesar das dificuldades impostas para o acesso a alguns dados institucionais, foi possível analisar, compreender e apresentar nesta pesquisa, como se dá a implementação da comissão de heteroidentificação, assim como os seus membros, atuações e atos regulatórios. Reforçou-se, ainda, a presença do NEAB/UNIFAP e o estabelecimento dessa parceria, que possibilitou a abertura para análises mais amplas, a considerar o conhecimento científico e social a respeito da população negra, das políticas de promoção da igualdade racial e na constante luta e atuação dentro e fora da UNIFAP.

No entanto, tal presença não anula a necessidade de capacitações frequentes para todos os membros da comissão de heteroidentificação, assim como momentos abertos para a comunidade em geral, o que proporcionará, maiores conhecimentos sobre as políticas de ações afirmativas, autodeclaração e o papel da comissão, além dos posicionamentos da universidade em meio a tudo o que foi apresentado. 


\section{Referências}

ALMEIDA. Silvio Luiz. Racismo estrutural. São Paulo: Sueli Carneiro, Ed. Jandaíra, 2020.

AMAPÁ. Universidade Federal do Amapá. Resolução nº 39, de 29 de novembro de 2017. Dispõe sobre o estabelecimento de ações afirmativas na universidade. Amapá: Conselho Universitário, 2017.

AMAPÁ. Universidade Federal do Amapá. Servidores participam de curso sobre racismo e políticas afirmativas, 2019.

AMAPÁ. Universidade Federal do Amapá. Edital nº05/2020 - DERCA/UNIFAP. Departamento de registro e controle acadêmico - DERCA., p. 01-09, 2020a.

AMAPÁ. Universidade Federal do Amapá. Edital nº06/2020 - DERCA/UNIFAP. Departamento de registro e controle acadêmico - DERCA., p. 01-11, 2020 b.

AMAPÁ. Universidade Federal do Amapá. Edital nº26/2020 - DERCA/UNIFAP. Departamento de registro e controle acadêmico - DERCA., p. 01-19, 2020c.

AMAPÁ. Universidade Federal do Amapá. UNIFAP cria comissão para avaliar ingresso de alunos cotistas e evitar fraudes. Site oficial, 2020d.

AMAPÁ. Ministério da Educação. Universidade Federal do Amapá. Portaria nº934, de 16 de julho de 2020. Dispõe sobre a comissão de matrícula e heteroidentificação SISU 2020, [2020e].

AMAPÁ. Ministério da Educação. Universidade Federal do Amapá. Portaria nº 0018, de 07 de janeiro de 2021. Dispõe sobre a comissão de heteroidentificação - análise de recurso processo seletivo 2020, [2021a].

AMAPÁ. Ministério da Educação. Universidade Federal do Amapá. Portaria n ${ }^{\circ} 0021$, de 07 de janeiro de 2021. Dispõe sobre a comissão de heteroidentificação análise no decorrer do processo seletivo 2020, [2021b].

BATISTA, Neusa Chaves; FIGUEIREDO, Hodo Apolinário Coutinho. Comissões de heteroidentificação racial para acesso em universidades federais. Cadernos de pesquisa, n. 177, p. 865-881, 2020.

BENTO, Maria Aparecida Silva. Branqueamento e branquitude no Brasil. In: CARONE, Iray; BENTO, Maria Aparecida Silva (org.). Psicologia social do racismo: estudos sobre branquitude e branqueamento no Brasil. Petrópolis, RJ: Vozes, p. 25-58, 2002.

BRASIL. Declaração e programa de ação. III Conferência mundial contra o racismo, discriminação racial, xenofobia e intolerância correlata, Durban - África do Sul, p. 01-101, 2001. Disponível em: Ácesso em: 29 dez. 2020.

BRASIL. Lei no 10.639, de 9 de janeiro de 2003. Brasília, DF: 2003.

BRASIL. Lei ñ 11.645, de 10 de março de 2008. Brasília, DF: 2008.

BRASIL. Lei no 12.288, de 20 de julho de 2010. Brasília, DF: 2010. 
BRASIL. Lei no 12.711, de 29 de agosto de 2012. Brasília, DF: 2012.

BRASIL. Lei no 12.990, de 9 de junho de 2014. Brasília, DF: 2014.

BRASIL. Portaria normativa $n^{\circ}$ 04, de 6 de abril de 2018. Brasília: DF: 2018.

CAMILLOTO, Bruno; OLIVEIRA, Rita Cristina. Comissões de heteroidentificação racial: os desafios políticos e jurídicos de implementação da política de ações afirmativas nas universidades públicas brasileiras. Revista ensaios e pesquisa em educação e cultura, n. 9, p. 86-100, 2020.

DANTAS, Sylvia; FERREIRA, Ligia; VÉRAS, Maura Pardini Bicudo. Um intérprete africano no Brasil: Kabengele Munanga. Revista USP, n. 114, p. 31-44, 2017.

FONTOURA, Maria Conceição Lopes. Tirando a vovó e o vovô do armário. In: DIAS, Gleidson Renato Martins; JUNIOR, Paulo Roberto Faber Tavares (org.). Heteroidentificação e cotas raciais: dúvidas, metodologias e procedimentos. Canoas: IFRS campus Canoas, p. 107-140, 2018.

GIL, Antônio Carlos. Métodos e técnicas de pesquisa social. 6. ed. São Paulo: Atlas, 2008.

HOFBAUER, Andreas. Ações afirmativas e o debate sobre o racismo no Brasil. Lua nova, n. 68, p. 9-56, 2006.

INSTITUTO BRASILEIRO DE GEOGRAFIA E ESTATÍSTICA (IBGE). Desigualdades sociais por raşa e cor no Brasil, 2012.

MELUCCI, Alberto. Por uma sociologia reflexiva: pesquisa qualitativa e cultura. Petrópolis, RJ: Vozes, 2005.

MUNANGA, Kabengele. Considerações sobre as políticas de ação afirmativa no ensino superior. In: PACHECO, Jairo Queiroz; SILVA, Maria Nilza (org.). O negro na universidade: direito a inclusão. Brasília, DF: Fundação Cultural Palmares, p. 07-20, 2007.

NEAB-UNIFAP. Núcleo de Estudos Afro-brasileiros. Gira de saberes: heteroidentificação e cotas raciais, (1 vídeo) $124 \mathrm{~min}, 2019$.

NOGUEIRA, Ari Fernandes Santos; LIMA, Iracema Oliveira. Impactos do racismo institucional na promoção de equidade na educação superior. VII Seminário Nacional e III Seminário Internacional: Políticas públicas, gestão e práxis educacional. Vitória da Conquista - BA, n. 7, p. 4396-4411, 2019.

NUNES, Georgina Helena Lima. Autodeclarações e comissões: responsabilidade procedimental dos/as gestores de ações afirmativas. In: DIAS, Gleidson Renato Martins; JUNIOR, Paulo Roberto Faber Tavares (org.). Heteroidentificação e cotas raciais: dúvidas, metodologias e procedimentos. Canoas: IFRS campus Canoas, p. 11-31, 2018.

OLIVEN, Arabela Campos; BELLO, Luciane. Negros e indígenas ocupam o templo branco: ações afirmativas na UFRGS. Horizontes Antropológicos, n. 49, p. 339-374, 2017. 
PARÁ. Universidade Federal do Pará. A partir do PS 2021, comissão de heteroidentificação vai analisar a autodeclaração de candidatos(as) negros(as). Site oficial, 2021.

RIOS, Roger Raupp. Pretos e pardos nas ações afirmativas: desafios e respostas da autodeclaração e da heteroidentificação. In: DIAS, Gleidson Renato Martins; JUNIOR, Paulo Roberto Faber Tavares (org.). Heteroidentificação e cotas raciais: dúvidas, metodologias e procedimentos. Canoas: IFRS campus Canoas, p. 215-150, 2018.

SANTOS, Dyane Brito Reis. Curso de branco: uma abordagem sobre o acesso e a permanência de estudantes de origem popular nos cursos de saúde da universidade federal do Recôncavo da Bahia (UFRB). Revista contemporânea de educação, n. 23, p. 31-50, 2017.

SILVA, Ana Claudia Cruz et al. Ações afirmativas e formas de acesso no ensino superior público: o caso das comissões de heteroidentificação. Revista Novo, n. 2, p. 329-347, 2020.

SILVÉRIO, Valter Roberto. Ação afirmativa: uma política pública que faz a diferença. In: PACHECO, Jairo Queiroz; SILVA, Maria Nilza (org.). O negro na universidade: direito a inclusão. Brasília, DF: Fundação Cultural Palmares, p. 21-47, 2007.

SITO, Luanda. Disputas e diálogos em torno do conceito de "ações afirmativas" para o ensino superior no Brasil. Universitas bumanistica, n. 77, p. 251-275, 2014.

TAVARES JR., Paulo Roberto Faber. Orientações práticas para a implementação da comissão de heteroidentificação em institutos federais de educação (IF'S). In: DIAS, Gleidson Renato Martins; JUNIOR, Paulo Roberto Faber Tavares (org.). Heteroidentificação e cotas raciais: dúvidas, metodologias e procedimentos. Canoas: IFRS campus Canoas, p. 251-272, 2018.

VAZ, Lívia Maria Santana e Sant'Anna. As comissões de verificação e o direito à (dever de) proteção contra a falsidade de autodeclarações raciais. In: DIAS, Gleidson Renato Martins; JUNIOR, Paulo Roberto Faber Tavares (org.). Heteroidentificação e cotas raciais: dúvidas, metodologias e procedimentos. Canoas: IFRS campus Canoas, p. 32-79, 2018. 